\title{
AVALIAÇÃo ARQUIVISTICA: Bases teóricas, estratégias de Aplicação e instrumentação
}

\author{
ARCHIVAL APPRAISAL: theoretical bases, strategies of application and \\ instrumentation
}

\author{
Basma Makhlouf - Basma.makhlouf@umontreal.ca \\ Doutoranda em Arquivologia /Escola de Biblioteconomia e Ciências da Informação \\ Universidade de Montreal \\ Lídia Eugenia Cavalcante - lídia@ufc.br \\ Doutora em Educação \\ Professora Adjunta Universidade Federal do Ceará \\ Pós-doutora em Ciências da Informação / Universidade de Montreal
}

\begin{abstract}
Resumo
A coerência dos vários componentes da função avaliação arquivística implica o respeito a três exigências: 1) evidência da teoria e dos conceitos constitutivos e capacidade especifica, o que representa o valor dos originais; 2) a capacidade da estratégia de avaliação integrar os conceitos que se relacionam ao valor dos originais como definido pela teoria; 3) a capacidade do processo institucional de sua aplicação conformar-se à estratégia e respeitar suas bases teóricas. Dessa forma, apresenta-se, primeiramente, um esboço do conceito "função" no contexto da avaliação arquivística. A seguir, discorre-se sobre bases teóricas, estratégias e métodos relacionados, técnicas e critérios de aplicação e, finalmente, a instrumentação de realização, de acordo com cinco autores-chave da avaliação arquivista: H. Booms (1970, 1972, 2002), H. Samuels (1986), T. Cook (1992, 1994, 1997, 1999), T. Eastwood (1992, 2002) e C. Couture (1998, 1999, 2002).
\end{abstract}

Palavras-chave: Avaliação arquivística. Função avaliação.

\section{INTRODUÇÃO}

Este trabalho originou-se de nossas pesquisas sobre avaliação arquivística, realizado na Escola de Biblioteconomia e de Ciências da Informação, da Universidade de Montreal Canadá. Tem como objetivo apresentar revisão de literatura relativas às bases teóricas, estratégias de aplicação e instrumentação utilizadas na área de Arquivo. Por conseguinte, abordaremos a temática proposta em cinco partes: 1) aporte teórico da função avaliação arquivistica; 2) estratégias de aplicação; 3) critérios de avaliação; 4) instrumentos da gestão; e, por fim, 5) uma síntese de estratégias diferentes de avaliação, das quais sublinharemos as particularidades, divergências, similaridades e complementaridades. Cada uma dessas seções será estudada sob o ponto de vista de cinco autores importantes no domínio da avaliação arquivísitca: H. Booms (1970, 1972, 2002), H. Samuels (1986), T. Cook (1992, 1994, 1997, 1999), T. Eastwood (1992, 2002) e C. Couture (1998, 1999, 2002).

A função avaliação suscita o interesse de vários autores e estudiosos em arquivística contemporânea. O termo "função" é seguidamente utilizado na literatura da área para distinguir a avaliação de outras intervenções arquivísticas, tal como a função aquisição ou 
difusão, por exemplo. Autores como Couture (1990), Ducharme (2002) e Craig (2004) discutem o termo "função" relativo à avaliação e apresentam base teórica, princípios e conceitos constitutivos importantes para essa ação, compreendendo as técnicas, instrumentos e critérios de avaliação. Como evoca Bárbara Craig (2004), a função avaliação é utilizada para designar, atualmente, tudo o que trata da determinação do valor dos documentos.

Por conseguinte, a coerência entre os componentes da função avaliação arquivística implica o respeito a três exigências: 1) tornar evidentes a teoria e seus conceitos constitutivos e a capacidade de precisar o que representa o valor dos documentos; 2) a capacidade da estratégia de avaliação em operacionalizar os conceitos relativos ao valor dos documentos, tal qual definido pela teoria; 3) a capacidade do processo de aplicação institucional com relação à estratégia a ser adotada, respeitando os fundamentos teóricos de acordo com as origens dos documentos, reflexões de que trataremos no decorrer do texto.

\section{AVALIAÇÃO ARQUIVÍSTICA: BASES TEÓRICAS}

\subsection{Valor e Teoria de Valor}

O vínculo entre a função avaliação arquivística e a noção de valor é estudada por vários autores da literatura contemporânea da área. Para Cook (1999), Couture (2002) e MenneHaritz (1994), o valor é um conceito central para a avaliação arquivística, pois esta consiste em determinar o valor dos arquivos.

O arquivista britânico Hilary Jenkinson (1922) reconhece a centralidade do valor em relação à qualidade dos documentos de arquivos públicos. Jenkinson interessou-se por estudar o valor dos documentos, primeiramente, numa perspectiva de prova administrativa. Os arquivos, de acordo com esse autor, representam também fonte de prova científica confiável. Dessa forma, o valor de prova é central em relação aos fundamentos da pesquisa histórica e, por conseguinte, esta fonte preciosa de documentação é responsabilidade do arquivista. O valor de prova, como definido por Jenkinson (1922), está fortemente ligado ao caráter único, autêntico e imparcial dos arquivos.

Schellenberg $(1956,1965)$ desenvolveu toda uma teoria de valor, pela qual se tornou conhecido, de acordo com Cook (1997), como o pai da avaliação arquivística. Essa teoria propõe dois tipos de valores aplicáveis ao contexto dos arquivos: valor primário e valor secundário.

\footnotetext{
Os valores inerentes aos registros públicos modernos são de dois tipos: valor primário para a gestão de criação e valor secundário para outras instâncias e utilizadores. Os documentos públicos são gerados para realizar as finalidades para as quais um organismo foi criado: administrativo, fiscal, legal e operacional. Os documentos públicos são preservados em uma instituição arquivística definida, porque têm um valor que existirá por longo tempo, mesmo depois que cessam de ser do uso corrente e porque terão valores importantes para outros usuários que não os atuais. (SCHELLENBERG, 1984, p.58)
}

Os anos de 1950 - data do aparecimento dos trabalhos de Schellenberg - tornaram-se decisivos para os fundamentos teóricos da arquivística. A teoria de valor influenciou consideravelmente os trabalhos de especialistas como Booms (1970, 1972, 2002), Samuels (1986), Cook (1992, 1994, 1997, 1999), Eastwood (1992, 2002) e Couture (1998, 1999, 2002). Nas discussões que se seguem, propomos aprofundar as idéias fundamentais, 
estratégias e métodos, critérios e a instrumentos da função avaliação arquivística, tal como foi entendida por esses autores.

\subsection{Estratégia de Avaliação: Idéias Fundamentais}

De acordo com Booms (1987, 2002), a avaliação arquivística deve se harmonizar aos princípios fundamentais seguintes:

a) a função avaliação arquivística visa, essencialmente, à composição de um patrimônio documental;

b) seu mérito está no fato de permitir preparar material documental necessário para a pesquisa histórica;

c) a avaliação é um processo de determinação de valor assegurado pelo arquivista. Este processo deve ser formal, sistemático e claramente definido;

d) como conceito central relativo à função avaliação, o valor dos documentos deve ser claramente definido, justificável e, sobretudo, contemporâneo à época ou ao período de sua criação. Neste sentido, Booms (1987, p. 104) acrescenta: “Construindo uma tabela conceitual histórica, que servirá de modelo à herança documental, os arquivistas não devem seguir os conceitos de valor de acordo com a sua própria época, mas antes, de acordo com o valor que governa a época na qual o material foi criado.";

e) os julgamentos do arquivista devem ser formulados a partir do contexto social. Este princípio, entretanto, supõe também que os documentos, como tais, não tenham valor intrínseco. Este valor é atribuído após a avaliação feita pelo arquivista. É importante salientar a esse respeito, porém, que o arquivista é chamado a ouvir a opinião de especialistas para deduzir os valores dominantes que regem tais documentos. Conseqüentemente, esse profissional deve ter uma visão global sobre o desenvolvimento social e as diferentes mudanças ocorrentes na sociedade. Em outros termos, a missão de identificação do valor dos documentos de arquivos que o arquivista é chamado a assegurar decorre, de acordo com Booms (1987), da realidade social e dos valores contemporâneos ao documento.

Samuels (1991) acentua a importância do princípio de proveniência e o respeito à originalidade dos documentos, estabelecidos por seu produtor, em relação ao processo da avaliação. De acordo com Samuels (1986), estes princípios clássicos da arquivística representam "meios metodológicos" porque permitem melhor visibilidade do universo dos produtores dos arquivos e de suas diversas funções e atividades que se deve documentar.

Por conseguinte, ainda para Samuels (1986), a pergunta fundamental que o arquivista deve se fazer no exercício da avaliação é a que se refere à natureza das funções do organismo produtor que deve documentar, antes mesmo de saber o conteúdo dos arquivos. Esta perspectiva difere um pouco da percepção de Booms (1987), que incitou os arquivistas a se interessarem, sobretudo, pela identificação dos valores de uma sociedade. Isto nos conduz a crer que Booms percebe a primeira etapa da avaliação arquivística como um ato teórico e conceitual, dado que visa à síntese da opinião pública para definir os diversos valores que regem a sociedade. Samuels (1986) situa-se em nível mais pragmático. Interessa-se, em primeiro lugar, pelas funções e atividades das diferentes instituições para as quais a função avaliação arquivística se realiza, como, por exemplo, a função de ensino, assegurada por universidades, escolas, ministérios da educação etc. 
De acordo com Cook (2002), a avaliação arquivística deve respeitar os seguintes princípios fundamentais:

a) a avaliação é um processo ativo, sistemático e planificado;

b) os documentos são avaliados diretamente pelo arquivista, após investigação exaustiva baseada em critérios prédefinidos;

c) avaliando os documentos, o arquivista é levado a estudar o universo estrutural no qual estes foram criados;

d) a avaliação é procedimento de determinação de valor. Não deve ser confundida com a aquisição, por exemplo;

e) sem teoria ou conceitos articulados que definem o valor dos documentos, nenhuma estratégia ou metodologia de avaliação será uniforme, uma vez que ela é posta em aplicação;

f) é importante distinguir a teoria de avaliação das outras teorias arquivísticas;

g) a avaliação é inevitavelmente um processo subjetivo, e os "valores" se modificarão com o tempo, o lugar e a cultura. O desafio para o arquivista é assinalar o passado, de modo que o futuro o saiba; e

h) em decorrência da complexidade da avaliação arquivística e de sua subjetividade, o arquivista deve ser capaz de justificar, documentar e defender as suas decisões em matéria de determinação dos valores dos documentos com a máxima transparência.

Para Eastwood (1992), a avaliação dos arquivos deve originar-se na análise dos documentos, do seu conteúdo e estrutura interna. Como processo que visa à determinação do valor desses documentos, a avaliação arquivística implica também uma análise dos valores sociais, pois estes últimos se refletem nas produções documentais das diferentes instituições da sociedade. A noção de valor dos documentos é fortemente ligada, segundo Eastwood (2002), aos valores da sociedade. Nessa mesma ordem de idéias, assinala:

\begin{abstract}
A avaliação dos documentos de arquivos numa sociedade democrática deve, de uma maneira ou de outra, servir às necessidades dos cidadãos de saber como viveram; por um lado, permitir-lhes compreender melhor o seu lugar nas comunidades às quais consideram fazer parte, incluindo naturalmente a comunidade nacional. (2002, p.49).
\end{abstract}

A análise do uso dos arquivos - presente e passado - e as diferentes necessidades que os justificam representam, de acordo com Eastwood (1992), elemento fundamental no que concerne à determinação do valor secundário dos documentos, pois esta permite melhor compreender e predizer o que poderia interessar ao usuário do futuro. Visivelmente, a abordagem de Easwood inscreve-se na teoria dos valores, porquanto que esta última atribui valor aos documentos em função da natureza do seu uso.

Couture (2002) assinala que a avaliação dos arquivos deve se apoiar sobre os cinco princípios diretores seguintes:

a) os arquivos representam uma prova privilegiada de todas as atividades do conjunto da sociedade. Booms (2002), Samuels (1986), Cook (1992) e Eastwood (1992) também reconheceram a importância deste princípio e afirmam que a avaliação arquivística deve se interessar pela particularidade dos arquivos e a sua capacidade de representar o contexto no qual foram criados; 
b) o respeito à objetividade e à contemporaneidade do julgamento. Assim, os arquivistas devem considerar os valores contemporâneos à época e ao lugar de criação dos documentos objeto da avaliação. Este princípio se junta perfeitamente aos propósitos de Booms (1987), concernentes à importância de respeitar a contemporaneidade dos valores da sociedade;

c) o respeito às relações que unem a avaliação com as outras funções arquivística; isto é, que o arquivista deve levar em consideração, na atividade de avaliação, outras funções arquivísticas, como a aquisição e a preservação, por exemplo. Por outro lado, Cook (2002) não parece ser partidário deste princípio. Para ele, a avaliação dos arquivos é distinta das outras intervenções arquivísticas;

d) o respeito ao equilíbrio entre finalidades da gestão e finalidades patrimoniais da avaliação. Este princípio implica que o arquivista deve ter bom conhecimento sobre aquilo que é valor primário, o qual se reporta às finalidades da gestão, e o que é valor secundário, que se refere às finalidades patrimoniais;

e) o respeito ao equilíbrio entre as considerações de criação $e$, notadamente, às que se referem ao contexto do seu uso. A consideração deste contexto de uso recorda as idéias de Schellenberg (1956), Eastwood (1991) e Samuels (1986). Todos confirmaram a importância de analisar os usos anteriores e atuais dos documentos em relação ao processo da avaliação arquivística. Cook (2002) não compartilha desta idéia com os autores citados. De acordo com esse autor, o uso dos documentos é a última dimensão a considerar no processo da avaliação. Segundo ele, a determinação do valor dos documentos, baseando-se na previsão dos seus usos ulteriores, representa uma missão difícil ou mesmo impossível.

Couture (2002) acrescenta a estes cinco princípios a centralidade da noção de valor, em relação às bases teóricas relativas à função avaliação arquivística. $\mathrm{O}$ autor corrobora com Schellenberg e define a teoria de valor:

\footnotetext{
O valor primário é a finalidade do documento de arquivo fundada sobre as suas utilidades primeiras, sobre as razões pelas quais existe. Trata-se, essencialmente, de prova administrativa, legal e financeira. $\mathrm{O}$ valor secundário é a finalidade do documento de arquivo fundada sobre as suas utilidades segundas ou científicas. $\mathrm{O}$ valor secundário é ligado à informação e ao testemunho que fornece o documento em relação à pessoa ou a um organismo que a criou ou recebeu, por um lado, e em relação à sociedade em geral, de outra parte.
}

Para melhor compreender como estes diferentes princípios teóricos articulam-se de fato, propomos aprofundar as diversas estratégias de avaliação e os métodos de aplicação aferentes, como entendidos pelos cinco autores-chave da avaliação arquivística por nós estudados: Booms, Samuels, Cook, Eastwood et Couture.

\section{ESTRATÉGIAS DE AVALIAÇÃO E MÉTODOS AFERENTES}

\subsection{H. Booms e o Plano Documental - "Documentation plan"}

Booms apresentou, em 1970, por ocasião da Conferência Anual dos Arquivos Alemães (MENNE-HARITZ, 1994), um modelo de avaliação que chamou de plano documental "Documentation plan". Esse modelo é inspirado em um método de avaliação arquivística utilizado pelo governo comunista da ex-Alemanha do Leste (MENNE-HARITZ, 1994), que consiste em analisar e documentar um conjunto de acontecimentos julgados importantes durante um período limitado (BOOMS, 2002). Estes são escolhidos pelos arquivistas, historiadores e autoridades oficiais, por sua pertinência e representatividade em 
relação à imagem da sociedade. De acordo com Booms (1987, 2002), a avaliação arquivística é a densidade qualitativa do conjunto da produção documental. Para esse autor, os arquivos deverão, antes de tudo, documentar as realidades sociais, compor o patrimônio documental da sociedade e refletir fielmente seus valores contemporâneos. A missão do arquivista, em matéria de avaliação, no âmbito de um plano documental, consiste em realizar uma análise histórica. Duas etapas principais devem ser previstas nesta análise: a) a análise contemporânea da opinião de especialistas; e b) a identificação dos acontecimentos significativos dignos de documentação (BOOMS, 1987, p.105). Este método de avaliação parece limitar o poder do arquivista em relação à escolha do acontecimento relevante à memória da organização/instituição, pois este último exige que o trabalho do arquivista seja supervisionado ou mesmo validado por historiadores e autoridades políticas (MENNE-HARITZ, 1994).

\subsection{H. Samuels e a Estratégia Documentária - "Documentation Strategy"}

A estratégia documentária - "Documentation Strategy" é uma abordagem da avaliação arquivística desenvolvida por Samuels (1986). Este método tem interesse de analisar as funções asseguradas pelo conjunto das instituições que parecem ser essenciais à sociedade. A missão do arquivista, de acordo com esta abordagem, consistirá em identificar e analisar as funções essenciais, objeto de uma documentação exaustiva. Importa notar que, neste caso, Samuels distingue dois níveis de análise: a) a análise das funções essenciais realizadas por várias instituições - "Documentação Strategy"; e b) a análise das funções asseguradas por várias estruturas de uma mesma instituição -"Institutional functional analysis".

Além disso, esta abordagem, que repousa sobre a análise funcional, foi parcialmente apreciada por Cook (1992). Bailey (1997) sublinha, neste sentido, a noção de que cada uma das duas estratégias de avaliação (a macro-avaliação e a "Documentation Strategy") adota uma abordagem lógica e planificada, baseando-se na análise exaustiva do contexto dos documentos e de seu criador.

\subsection{T. Cook e a Macro-avaliação}

Cook (1992) apresentou outra estratégia para determinar o valor dos documentos. Esta estratégia, chamada macro-avaliação, far-se-á essencialmente a partir da análise de estruturas, funções, atividades, missões e produção documental da estrutura produtora dos documentos, por meio de uma visão atenta das relações entre esses diferentes componentes. Importa notar que a análise funcional, como descrita nesta abordagem, difere daquela apresentada por Samuels (1986, 1991 e 1992) no âmbito da "Documentação Strategy". Esta última é uma análise que interessa a uma dada função, assegurada por várias instituições, como, por exemplo, a função educativa. A documentação desta função interessará a diferentes instituições, como universidades, ministérios da educação etc. Contrariamente a esta análise interinstitucional, Cook (1992, 2002) apresenta a análise funcional das estruturas organizacionais de uma mesma instituição, ou seja, intrainstitucional.

As estruturas organizacionais nos oferecem, de acordo com Cook (1992), uma representação bastante fiel à lógica específica do seu produtor. Isto nos permite também melhor compreender o modelo de gestão da unidade administrativa, bem como a dinâmica mediante a qual esta interage com o seu meio interno e externo num contexto organizacional amplo. 
Booms (2002) sublinha, no seu artigo Ordre social et constitution du patrimoine archivistique: à propos de l'évaluation des sources d'archives, a importância das estruturas e das instituições em geral, no tocante à determinação do valor dos documentos. Booms recorda também que a avaliação deve fazer-se partindo de conhecimento bastante aprofundado das instituições produtoras, componentes da sociedade.

Por outro lado, Samuels rejeitou a centralidade do estudo da estrutura organizacional em relação ao processo da avaliação arquivística. Para ele, este último é uma pista frágil e movente. Em contrapartida, Samuels $(1986,1991)$ reconhece que o estudo da estrutura organizacional é uma etapa secundária na avaliação arquivística, pela qual o arquivista deve se interessar. E, após ter identificado, analisado e documentado, as funções principais refletem os valores de uma sociedade.

\subsection{T. Eastwood e a Micro-avaliação}

Eastwood (1992) propôs a estratégia da micro-avaliação como abordagem diferente das precedentes. Esta consiste em avaliar os documentos, com respaldo da análise exaustiva do corpus documental, sua estrutura geral, seus componentes, a relação orgânica entre as diversas secções etc. Eastwood (1992) sublinha a noção de que a avaliação deve interessarse igualmente pelas informações relativas aos valores organizacionais do usuário do passado e do presente dos documentos. Esta análise do uso e de suas tipologias fornece elementos relevantes que permitem ao arquivista elaborar o perfil do usuário potencial. Com efeito, esta missão parece ser um pouco mais complexa do que no entender de Eastwood. Tal complexidade reside na dificuldade para predizer a tipologia dos usuários potenciais.

O interesse no uso dos documentos, quando da determinação do seu valor evocado por esta estratégia, não é completamente novo. Encontramos também esta idéia presente na teoria de valor, de Schellenberg (1956), que primeiro classificou o valor dos documentos de acordo com a natureza do seu uso primário e secundário, para lembrar continuamente aos arquivistas sobre a importância do usuário potencial dos arquivos na avaliação.

\subsection{Carol Couture e a Avaliação Integrada}

Couture (2002) assinala que a avaliação dos arquivos se realiza por meio de um processo de duas fases: a primeira, de macro-avaliação e a segunda, de micro-avaliação. Neste sentido, o autor acrescenta:

\footnotetext{
A elaboração da tabela de temporalidade deve necessariamente realizar-se em duas grandes etapas que são a macro-avaliação e micro-avaliação [... ]. Entende-se por macro-avaliação a primeira fase a que o arquivista preocupa-se mais com as razões pelas quais o documento existe, mandatos e funções do criador, estabelecimento de prioridades por meio das quais as unidades administrativas a estudam. (Cook, 1992, p. 47) [... ]. A micro-avaliação, quanto a ela, é esta segunda fase que se situa ao nível das operações e que visa julgar o valor primário e o valor secundário que apresentam os documentos arquivisticos, estabelecendo as regras de conservação que serão reagrupadas na tabela de temporalidade. (p. 52).
}

Com efeito, Couture (1998, 1999, 2002) adotou abordagem conciliadora, fiel à arquivística contemporânea integrada, baseada também numa diligência analítica, desenvolvida desde uma perspectiva social. Para Couture (2002), a macro-avaliação e a micro-avaliação constituem duas etapas complementares a se realizarem em uma só 
estratégia de avaliação. Cada uma dessas tarefas nos remete ao interesse em analisar uma dimensão determinante quanto à identificação do valor dos documentos.

\section{CRITÉRIOS DE AVALIAÇÃO}

Por volta dos anos de 1980-90, vimos surgir uma tendência arquivística interessada no desenvolvimento de tabelas de critérios de avaliação. Este interesse explica-se pela complexidade em determinar o valor dos documentos, favorecendo a emergência de certa necessidade profissional. $\mathrm{O}$ arquivista não se sentia suficientemente equipado para realizar a missão de avaliador dos arquivos. Nesta perspectiva, os critérios de avaliação foram apresentados como balizas de orientação para prestar a assistência e o apoio necessários a fim de garantir melhor emprego da avaliação dos arquivos. Os esforços despendidos na concepção e elaboração das tabelas de critérios de avaliação dos arquivos eram orientados principalmente com o objetivo de estruturar as considerações necessárias para compor o patrimônio pessoal, institucional e social.

De acordo com Booms (2002), o arquivista deve reportar-se a vários critérios quando do julgamento do valor dos documentos. Estes permitem definir, de fato, o valor documental. Em outras palavras, os critérios de avaliação permitem operacionalizar o conceito de valor. Booms (2002, p. 17) sublinha igualmente que "os critérios de avaliação devem ser compreensivos e significantes e, ao mesmo tempo, claros e suficientemente concretos." Ou seja, Booms não propusera critérios de avaliação, mas apresentara os qualificativos pretendidos para um conjunto de critérios de avaliação. Com efeito, esse autor reconhece que o desenvolvimento de critérios de avaliação concretos é uma missão difícil ou até mesmo "impossível". (p. 18).

Para Samuels (1986), Eastwood (1992) e Cook (2002), o desenvolvimento de critérios de avaliação é necessário para uma prática uniforme e guiada. Cook (1991, 2002), por outro lado, sublinha a noção de que a avaliação arquivística deve se apoiar em critérios claramente definidos pelo arquivista. Com a ajuda destes critérios, o arquivista justifica a preservação dos documentos em razão do seu valor informacional. Cook (2002) propõe ainda um conjunto de critérios gerais para orientar o arquivista na determinação do valor secundário dos documentos governamentais e, mais particularmente, o valor de informação. Os critérios por ele propostos são: a) a integralidade das séries de arquivos, b) a autenticidade dos documentos, c) a unicidade das unidades de arquivos, d) a relação com outros documentos, e) datas e lapsos que cobrem os arquivos (antiguidade), f) a extensão, g) facilidade de utilização, h) facilidade de manipular o documento em seu suporte, e, por fim, i) as condições materiais dos documentos.

Couture (2002) assinala que até agora a arquivística contemporânea não teve êxito ao desenvolver critérios de avaliação aplicáveis a todos os tipos de arquivos e que isto não deve estar entre as prioridades do arquivista. Para Couture, o arquivista pode desenvolver critérios de avaliação inspirados nas especificidades institucionais do organismo produtor dos documentos.

\section{INSTRUMENTAÇÃO}

Acerca dos instrumentos relativos à realização do processo da avaliação arquivística, importa notar que Couture $(1998,1999,2000,2002)$ é o primeiro a evocar esta dimensão 
meramente pragmática. Apesar do estímulo à operacionalização dos valores e critérios de avaliação, as estratégias apresentadas por Booms (1987), Samuels (1986, 1991 e 1992) e Cook $(1992,2002)$ não forneceram ferramentas ou instrumentos que permitissem a gestão desta função arquivística.

De acordo com Couture (2002), a avaliação arquivística deve permitir a determinação dos valores dos documentos e, em seguida, o arquivista é conduzido a propor prazos de conservação e consignação às suas decisões relativas a esse processo. A tabela de temporalidade será, então, o instrumento aferente, no qual serão consignadas as decisões relativas ao destino final dos documentos, e que servirá também de norma de conservação. A Biblioteca e Arquivos Nacionais do Quebec (2005) acentua que:

A tabela de temporalidade é um instrumento que determina os períodos de utilização e os suportes de conservação dos documentos ativos e semi-ativos de um organismo e que indica quais documentos inativos são conservados de maneira permanente e quais são eliminados. Contêm essencialmente regras de conservação que se aplicam a séries, às vezes documentos. De acordo com o artigo 7 da Lei sobre os arquivos, todo organismo público deve estabelecer e ter atualizada uma tabela de temporalidade dos seus documentos.

Por conseguinte, a tabela de temporalidade representa um instrumento da gestão importante e uma contribuição considerável no âmbito da prática de avaliação arquivista.

\section{SÍNTESE DAS ESTRATÉGIAS DE AVALIAÇÃO EM ARQUIVÍSTICA CONTEMPORÂNEA}

De acordo com o estudo exploratório realizado, podemos constatar que as diferentes abordagens apresentadas sobre avaliação arquivística, com assento nas reflexões dos autores estudados, reúnem propostas, cada um à sua maneira, para sublinhar cinco idéias fundamentais:

a) a primeira idéia que destacamos na seqüência do exame destas estratégias é a sua adesão a uma tendência social desenvolvida nos anos de 1980 pelo arquivista alemão Hans Booms. Visivelmente, essas estratégias de avaliação que abordamos adotaram esta finalidade de assegurar a constituição de um patrimônio documental da sociedade. Esta abordagem revela-se preocupada com a representatividade dos documentos e a sua capacidade de confirmar as diferentes estruturas, funções e atividades das diversas instituições de uma sociedade;

b) a segunda idéia reside no fato de que cada uma das estratégias adotou uma abordagem analítica. Assim, Booms exprime claramente que um plano documental que visa à constituição de um patrimônio não deve ser feito apenas respaldado na análise histórica e sociopolítica dos fenômenos significativos da sociedade. A estratégia de micro-avaliação parte da análise do corpus documental, enquanto que a macro-avaliação se orienta em direção à análise do contexto do organismo produtor. Por outro lado, Couture (2002) adotou uma abordagem baseada na análise do contexto estrutural dos próprios documentos. Além disso, a "Documentation Strategy" se preocupa com a identificação e a análise das funções principais asseguradas pelas diversas instituições de uma sociedade;

c) com relação aos principais conceitos que definem a natureza da avaliação arquivistica, os cinco autores estudados apresentam a mesma compreensão. Booms (2002), Samuels

Enc. Bibli: R. Eletr. Bibliotecon. Ci. Inf., Florianópolis, n. 26, $2^{\circ}$ sem.2008 
(1986), Cook (1991), Eastwood (1991) e Couture (2002) definiram claramente esta função como um processo de análise que concerne a três componentes principais: os documentos (estrutura documental), o produtor (estrutura geral, missões, funções, atividades, e as relações internas e externas entre estes componentes) e, notadamente, os temas que representam a sociedade. Independentemente da ordem de importância, cada um destes componentes deve ser estudado durante a avaliação dos documentos;

d) todas as estratégias de avaliação arquivística reúnem-se para confirmar que o arquivista é o agente principal da avaliação. Esta função implica a intervenção de outros agentes, como o produtor e o usuário, que poderão auxiliar sobre a determinação do valor dos documentos. A avaliação, entretanto, em termos de responsabilidade e processos de realização, repousa entre as missões essenciais da profissão de arquivista. Conseqüentemente, as estratégias de avaliação contradizem Jenkinson (1922), quando ele advoga a idéia de que o papel do arquivista é limitado à tarefa de simples guardião de arquivos, deixando assim a missão da avaliação dos documentos ao seu produtor; e

e) todas as estratégias abordadas reconhecem, cada uma à sua maneira, a teoria de valor desenvolvida por Schellenberg (1956) e, notadamente, a centralidade da noção de "valor" pertinente à função avaliação.

É importante salientar que as estratégias de avaliação arquivística divergem na primeira etapa que desencadeia a avaliação. Assim a "Documentation Plan" (BOOMS, 1987) aconselha os arquivistas a começarem pela análise da opinião de especialistas para identificar os valores sociais essenciais, necessários para documentar. Já a "Documentation Strategy" (SAMUELS, 1986) propõe começar pela identificação das funções fundamentais de uma sociedade, por exemplo: educação, saúde etc. Quanto a macro-avaliação Cook (1992) e Couture (2002) sugerem partir inicial e principalmente do estudo do contexto dos documentos e, notadamente, pela análise das estruturas do organismo produtor, as suas funções, missões e atividades. Para a micro-avaliação (EASTWOOD, 1992), a primeira etapa da avaliação é a análise dos documentos, ou seja, seu conteúdo, estrutura geral e, evidentemente, as relações orgânicas. A divergência principal entre estas estratégias é, sem dúvida, apenas uma questão de ênfase em relação ao processo de avaliação arquivística. Conseqüentemente, cada estratégia procurou dar prioridade, na realização deste processo, a uma dessas dimensões, sem negar a importância de recorrer a outras dimensões complementares para completar e aprofundar a análise da dimensão principal.

Em conclusão, constatamos que, em uma síntese das diferentes estratégias de avaliação apresentadas pelos autores estudados, há pelo menos o mesmo objetivo que é o da constituição de um patrimônio da sociedade. Este propósito é alcançado graças a um processo analítico. A avaliação dos documentos não se limita unicamente à análise dos valores sociais ou organizacionais, ao exame das funções essenciais que os documentos apresentam "Documentation Strategy", o estudo dos documentos "micro-avaliação", a tipologia do seu uso ou ainda à análise do contexto do organismo produtor "macroavaliação", unicamente. A avaliação arquivista necessita de cada uma dessas dimensões que, por meio de uma visão mais ampla, se concretiza com maior pertinência e eficácia no trabalho do arquivista. 


\section{REFERÊNCIAS}

BOOMS, H. Society and the Formation of a Documentary heritage : issues in the appraisal of archival sources. Archivaria, n. 24, p.69-107. 1987.

BOOMS, H. Ordre social et constitution du patrimoine archivistique. À propos de l'évaluation des sources d'archives. Archives, vol. 33, n. 3-4 , p. 7-44, 2001-2002.

BIBLIOTHEQUE ET ARCHIVES NATIONALES DE QUEBEC . Disponível em http://www.banq.qc.ca/portal/dt/services/archivistique_ged/crggid/crggid_outils/calendrier/ calendrierl.jsp . Acesso em: mar. 2007.

COOK, T. Documentation Strategy. Archivaria. n 34, p. 181- 191, summer 1992.

COOK, T. Mind over Matter: towards a new theory for archival appraisal. In.: CRAIG, Barbara L. (dir.). The Archival Imagination: essays in honour of A. Taylor. Ottawa: Association of Canadian Archivists, 1992, p. 38-70.

COOK, T. Another Brick in the Wall: terry Eastwood's Masonry and Archival Wall, History, and Archival Appraisal. Archivaria. n. 37, p. 96-103, spring 1994.

COOK, T. What is past is prologue: A history of archival ideas since 1898, and the future paradigm shift. Archivaria, 43, spring 1997. Disponível em:

http://www.mybestdocs.com/cookt-pastprologue-ar43fnl.htm . Acesso em fev. 2007.

COOK, T. Archival appraisal and collection: issues, challenges, new approaches. NARA 2 Auditorium: College Park, Md., USA. 22 April 1999. Disponível em: http://www.mybestdocs.com/cookt-nara-990421-2.htm. acesso em: fev. 2007.

COOK, T. Méthodologie d'évaluation : macro-évaluation et analyse fonctionnelle. Partie B: lignes directrices pour l'évaluation archivistique des documents gouvernementaux. 2000. Disponível em : http://www.collectionscanada.ca/gestioninformation/061102_f.html. Acesso em: Fev. 2006.

COOK, T. Appraisal Methodology. Library and Archives Canada, Information Management Services. Disponível em: http://www.collectionscanada.ca/informationmanagement/061101_e.html. Acesso em: dez. 2006

COOK, T. Postmodernism and the Practice of Archives. Archivaria, n. 51, p. 14-35, spring 2001.

COOK, T. Macro-appraisal and Functional Analysis: the Importance of Governance Rather than Government. Colloque international des sciences de documentation. Congrès des archives de Castilla y León, Département de Bibliothéconomie et de Documentation. Université de Salamanque, Espagne, 2002.

COUTURE, C. Archival Science and concept of record. In: Rapport du deuxième conférence de Stockholm, p. 11-25, 30- 31 may 1996.

COOK, T. Évaluation des archives et calendriers de conservation. Arbido, n. 7/8, 1998, p.10- 13.

COOK, T. Les Fonctions de l'archivistique contemporaine. Québec : Presse de l'Université du Québec, 1999.

COUTURE, C. ; DUCHARME, D. ; ROUSSEAU, J.Y. L’archivistique a-t-elle trouvé son identité ? Argus, v.17, juin. 1988. 
COUTURE, C. ; LAJEUNESSE, M. Législations et politique archivistique dans le monde, Québec, 1993..

COUTURE, C. ; ROUSSEAU, J.Y. Les archives au XXe siècle : une réponse aux besoins de l'administration et de la recherche. Montréal : Université de Montréal, 1982.

COUTURE, C. ; ROUSSEAU, J.Y. Les Fondements de la discipline l'archivistique. Collection gestion de l'information. Québec : Presse de l’Université de Québec, 1994.

COUTURE, C. La fonction évaluation en archivistique contemporaine: Une synergie entre plusieurs considérations complémentaires. Colloque international des sciences de documentation. Congrès des archives de Castilla y León, Département de bibliothéconomie et de documentation. Université de Salamanque, Espagne. 2002.

EASTWOOD, T. The Archival Fonds: from theory to practice. Ottawa : Bureau of Canadian Archivists. Planning Committee on Descriptive Standards, 1992.

EASTWOOD,T. Archival appraisal in democratic societies. Colloque international de sciences des documentation. Congrès des archives de Castilla y León, Département de bibliothéconomie et de documentation. Université de Salamanque, Espagne. 2002.

QUEBEC. La loi québécoise sur les archives. Disponível em :

http://www.anq.gouv.qc.ca/conseil/loiarchives.htm . Acesso em set. 2006.

SAMUELS, H. Who Controls the Past? The American Archivist, v. 49, n.1, p.109-124, spring 1986.

SAMUELS, H. Improving Our Disposition: Documentation Strategy. Archivaria, v. 33. p. 125-140, winter 1991-1992.

SAMUELS, H. Varsity Letters: Documenting Modern Colleges and Universities, The Society of American Archivist, Metuchen, N.J.\& London, The Scarecrow Press Inc.,1992.

SCHELLENBERG, T. The Appraisal of Modern Public Records. Bulletin of the National Archives, n. 8, p.6-7. october 1956.

SCHELLENBERG, T.The Management of Archives. New York: Columbia University Press, 1965.

SCHELLENBERG, T. The Appraisal of Modern Public Records, Modern Archives Reader: Basic Readings on Archival Theory and Practice. National Archives and Records Service, p. 57-70, 1984.

MENNE-HARITZ, A. Appraisal or documentation: can we appraise archives by selecting content? The American Archivist, v. 57, n. 3, p. 528-542. 1994.

\footnotetext{
ABSTRACT

The coherence of the various components of the function of the archival appraisal implies the respect of three requirements: 1) the clearness of the theory and its constitutive concepts and their capacity to specify that is what represents the value in the documents; 2) capacity of the strategy of appraisal to integrate the concepts relating to the value of the documents as defined by the theory; 3) and obviously, capacity of the institutional process of application to conform to the strategy and to respect its theoretical bases. In this paper, we should present firstly a short outline on the concept "function" in the context of archival appraisal. We approach then its components with knowing the theoretical bases, the related strategies and methods, the techniques and the criteria of its application and finally the instrumentation of realization, according to five key authors of the archival
} 
appraisal: H. Booms (1970, 1972, 2002), H. Samuels, (1986), T. Cook, (1992, 1994, 1997, 1999), T. Eastwood (1992, 2002) et C. Couture (1998, 1999, 2002).

KEYWORDS: Archival appraisal. Function of the archival appraisal.

Originais recebidos em: 07/11/2007

Texto aprovado em: 02/09/2008 